\title{
Technical note: A facility for respiration measurements in cattle
}

\author{
F. S. Machado, ${ }^{* 1}$ T. R. Tomich, ${ }^{*}$ A. L. Ferreira, ${ }^{*}$ L. F. L. Cavalcanti, $†$ M. M. Campos, ${ }^{*}$ C. A. V. Paiva, ${ }^{*}$ \\ M. N. Ribas, $†$ and L. G. R. Pereira* \\ *Brazilian Agricultural Research Corporation, Embrapa Dairy Cattle, Juiz de Fora, Minas Gerais, Brazil, 36038-330 \\ †Conselho Nacional de Desenvolvimento Científico e Tecnológico, Programa Recursos Humanos em Áreas Estratégicas (CNPq RHAE SEVA), \\ Intergado Tecnologia, Contagem, Minas Gerais, Brazil, 32280-300
}

\section{ABSTRACT}

A respiration system consisting of 4 climate-controlled chambers and 1 set of flowmeters and analyzers was constructed and validated. Each chamber had volume of $21.10 \mathrm{~m}^{3}(3.68 \times 2.56 \times 2.24 \mathrm{~m})$ and was made from steel with double-glazed windows on either side enabling visual contact between animals. The chambers are independently climate-controlled and can maintain temperature and relative humidity in a range from 5 to $45^{\circ} \mathrm{C}$ and 30 to $80 \%$, respectively. A flow generator and mass flowmeter continuously pull air from each chamber and a slight negative pressure inside the chamber is ensured. Air from all chambers and ambient air share a common gas analysis and data acquisition system for monitoring $\mathrm{O}_{2}, \mathrm{CO}_{2}$, and $\mathrm{CH}_{4}$ concentrations over the measurement period, with the cycle time set to $20 \mathrm{~min}$. Analyzers are regularly calibrated and the chambers have mean recoveries of 99.0 and $98.0 \%$ for $\mathrm{CO}_{2}$ and $\mathrm{CH}_{4}$, respectively. The chambers are equipped with infrared cameras and electronic feed and water bins for intake measurements, as well as sensors for monitoring animal position and heart rate. Data acquisition and analysis software is used to calculate the rate of consumption of $\mathrm{O}_{2}$ and production of $\mathrm{CO}_{2}$ and $\mathrm{CH}_{4}$. The dynamic respiration measurements are integrated with feed intake data and other sensors. The daily gas exchanges are estimated by integration to determine methane emission and heat production. We conducted a trial with 12 lactating $3 / 4$ Holstein $\times 1 / 4$ Gyr crossbred dairy cows (6 multiparous and 6 primiparous) under 2 feeding regimens (ad libitum or restricted) to validate the system. Two 22-h respiration measurements were obtained from each cow. Restricted-fed cows showed lower values for milk yield, methane emission, and heat production compared with ad libitum-fed animals. We found no difference between groups for $\mathrm{CH}_{4}$ produced

Received August 21, 2015.

Accepted February 9, 2016.

${ }^{1}$ Corresponding author: fernanda.machado@embrapa.br per kilogram of dry matter intake. Repeatability for $\mathrm{CH}_{4}$ emission and heat production was high (0.97 and 0.92 , respectively). The respiration system described herein is a useful tool for measuring the dynamic and accumulated data of heat production, methane emission, and feed intake.

Key words: bioenergetics, energy, indirect calorimetry, methane

\section{Technical Note}

Historically, open-circuit respiration chambers have been widely used in North America and Europe for determination of feed evaluation and energy requirements for dairy and beef cattle (Yan et al., 1997; Derno et al., 2005). Over the last decade, the increased demand for finding strategies to mitigate methane emission by ruminant animals has renewed interest in respirometry studies around the world. In addition, there is a need to understand the mechanisms that regulate energy expenditure in beef and dairy cattle to improve the efficiency of production and animal health (Derno et al., 2009), and to identify variation in energy metabolism of more-efficient animals as a phenotypic feature for breeding programs (Arndt et al., 2015; Moraes et al., 2015). The search for knowledge about the effects of heat stress on animal metabolism also motivates the use of climate-controlled respiration chambers. The respiration chambers for cattle described herein were designed to allow the study of interactions and dynamics among feed intake, climatic conditions, methane emission, and energy metabolism. The aim of this technical note is to describe and validate this facility as a useful and repeatable tool for respiration measurements.

The respiration system is located in Bioenergetic Laboratory of Multi-use Complex on Livestock Bioefficiency and Sustainability of the Brazilian Agricultural Research Corporation, Embrapa (Coronel Pacheco, Minas Gerais, Brazil). All chambers are located in the same building and a dedicated level on the second floor contains the air-conditioning units. A separate air-conditioned room, annexed to the chamber build- 


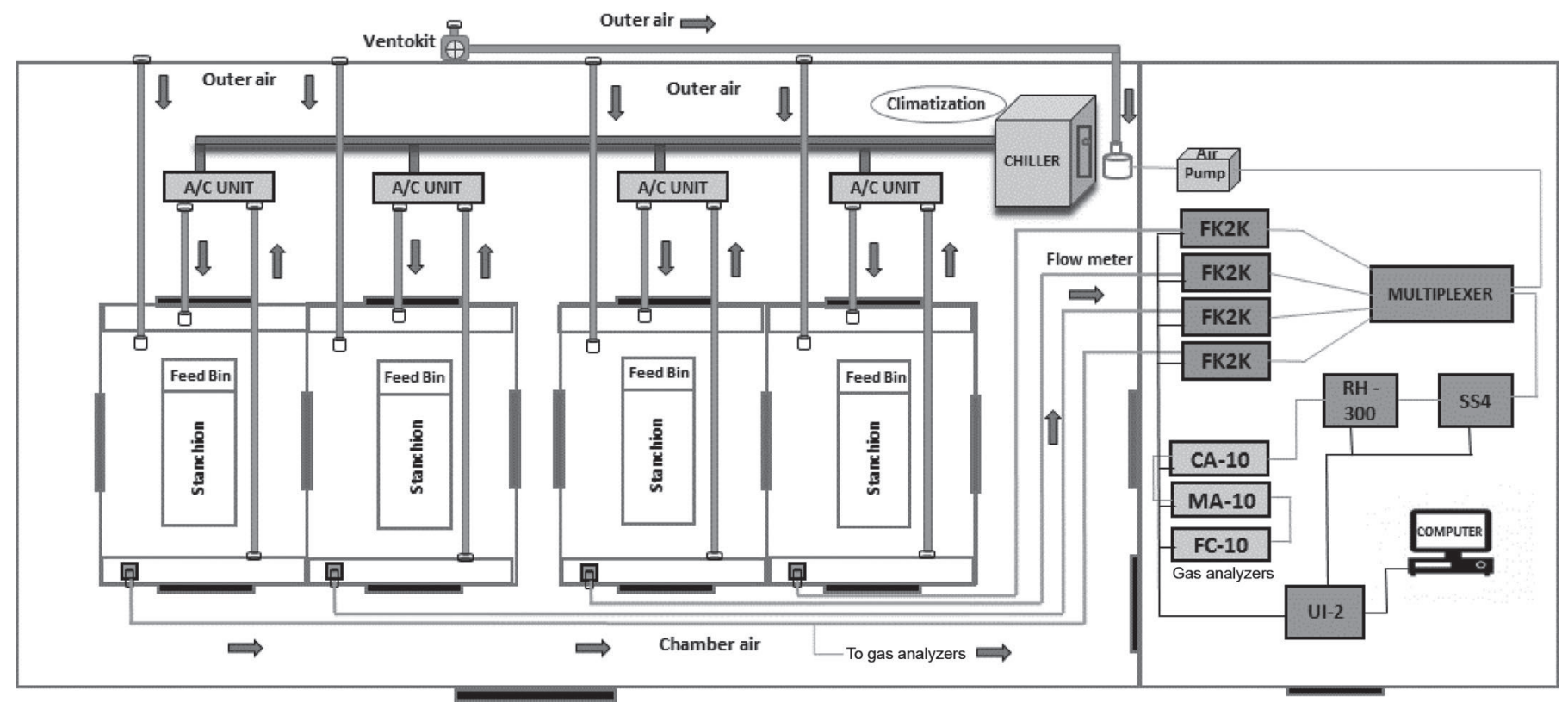

Figure 1. General scheme of the respiration system. FK2K = flow meter and control, SS4 = sub-sampler pump, RH-300 = water vapor analyzer, CA-10 $=\mathrm{CO}_{2}$ analyzer, MA-10 $=\mathrm{CH}_{4}$ analyzer, FC-10 $=\mathrm{O}_{2}$ analyzer, UI-2 = universal interface. All components are from Sable Systems International (Las Vegas, NV).

ing, houses the equipment for gas analysis, calibration, chamber control, and data acquisition and processing (Figure 1). The respiration system is configured in an open-circuit arrangement (Aguilera and Prieto, 1986) and consists of 4 chambers assembled in pairs. The net volume of each chamber is $21.10 \mathrm{~m}^{3}$, with dimensions $(\mathrm{m})$ of 3.68 long $\times 2.56$ wide $\times 2.24$ high, containing a $2.26-\times 1.26-\mathrm{m}$ pen, which provides a safe environment for one animal and allows technicians walk around to manipulate it. The construction company was No Pollution Industrial Systems Ltd. (Edinburgh, UK). The chambers are made from steel with thermo-insulating and sound-insulating wall panels made from AISI 304 stainless steel sheets (CPC Inox S.P.A., Basiano, Italy), with polyurethane injected in between. Joints between panels were sealed with polyurethane sealant (Sikaflex, Sika S/A, São Paulo, Brazil). The chambers have large double-glazed windows (150 cm high, $150 \mathrm{~cm}$ wide) to guarantee visual communication between animals. Each chamber is fitted with one large back door for animal access and a smaller front door for operator access and for feeding, both fitted with rubber seals (Figure 2A). The floor is concrete painted with epoxy to prevent $\mathrm{CO}_{2}$ exchange. An epoxy sealant ensures no leakage between the walls and concrete floor. A slurry grate located behind each animal is emptied twice a day by a flushing system operated from outside the chambers (Figure 2C). The slurry system is sealed with a wafer cast iron butterfly valve to prevent gas leaks. The pen floor is covered with a Rubber Plus mat (WingFlex, Kraiburg TPE GmbH \& Co., Waldkraiburg, Germany) to optimize the animal's comfort. Each chamber is fitted with an emergency hatch, which is closed by an electromagnet lock. In the event of a power failure, flooding due to a leak in the water supply system, extreme temperatures, or a $\mathrm{CO}_{2}$ build-up to $10,000 \mathrm{ppm}$, the hatch is automatically opened, ensuring animal safety.

Chambers are climate-controlled and designed to keep ambient temperature and relative humidity $(\mathbf{R H})$ from 5 to $45 \pm 0.5^{\circ} \mathrm{C}$ and 30 to $80 \pm 5 \%$, respectively. The temperature and $\mathrm{RH}$ inside the chambers are continuously measured over the measurement period, and the climate control and climatic conditions are recorded using Metasys software (version 5.1.3.0400; Johnson Controls Inc., Milwaukee, WI). Each chamber has an independent regulation system, a separate air treatment unit with a recirculating fan $\left(800-1,600 \mathrm{~m}^{3} / \mathrm{h}\right)$, and an air filter section, which is integrated to the chamber through 350-mm-diameter flexible thermo-insulating tubes. For recirculation, air leaves the chamber through openings at the bottom corners of the chambers. The air is then recycled into the chamber through openings at the front end of the chamber ceiling.

Four separate streams of ambient air are drawn through 75-mm-diameter polyvinyl chloride (PVC) pipes from outside the shed and are connected to each chamber's fresh air inlet in the front ceiling (Figure 1). 
A

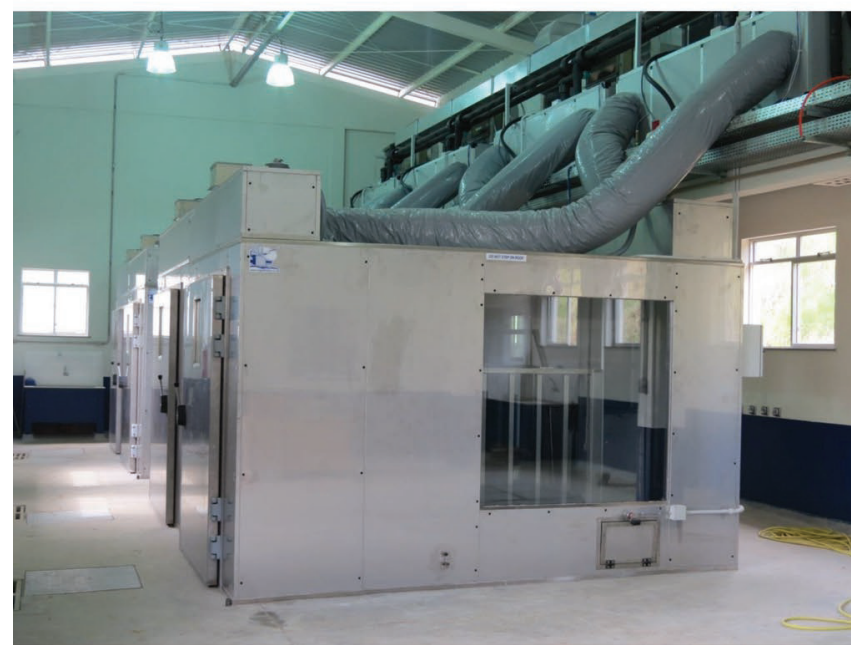

B

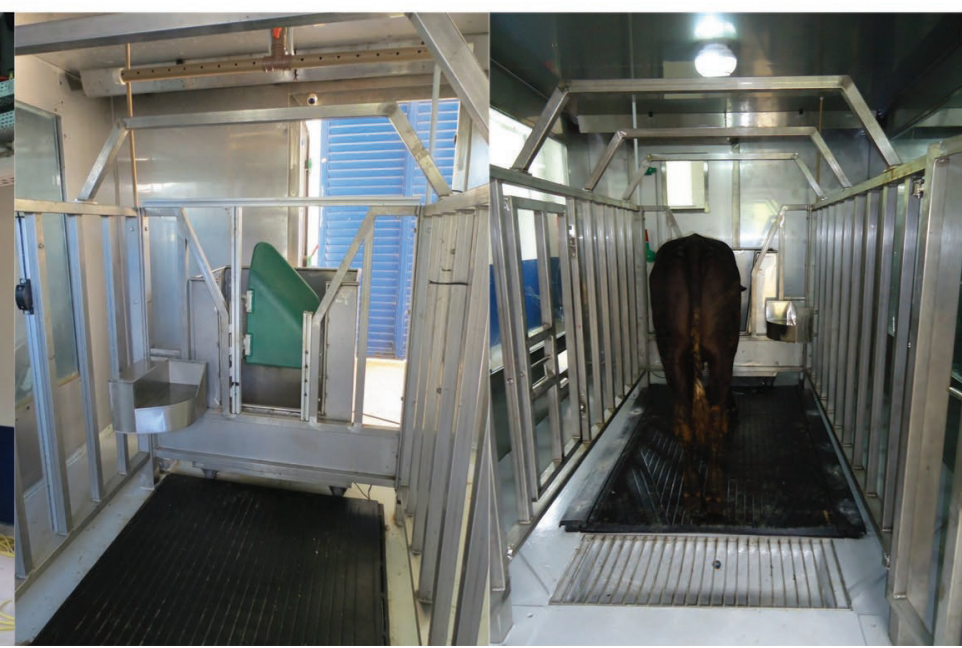

Figure 2. (A) Overview of the chambers; (B) chamber's interior view with the feed and water bins; (C) slurry grate for feces and urine. Color version available online.

Inside the chamber, the fresh air inlet presents a valve and a T-connection fitted with 2 horizontal PVC tubes $(50 \mathrm{~mm}$ diameter $\times 1.5 \mathrm{~m})$ punctured with 5 -mm holes to avoid laminar flow, immediately above the feed bin and next to recirculating air entrance. At the same shed wall, next to the 4 outside spots, another 75 -mm-diameter PVC pipe connected to an exhaust fan (Ventokit 80, Westaflex Tubos Flexíveis Ltda., Paraná, Brazil) is used to take the ambient air to a carboy next to the control room (Figure 1) so that more stable values of oxygen concentration can be obtained.

The chamber is fitted with an air outlet with a filter box (CSL-851-200HC, Solberg Manufacturing Inc., Itasca, IL), in the rear section of the ceiling, and the air is continuously drawn out through a 75 -mm-diameter PVC pipe, which is reduced to 51-mm-diameter flexible polyurethane hose next to the analysis room and then connected directly to a mass flowmeter and flow generator (FlowKit model FK-2000, Sable International Systems, Las Vegas, NV) with a sealed rotary pump having a capacity range from 400 to 2,000 L/ min. Flowmeters provide mass flow measurements of the atmospheric air corrected for standard temperature $(273.5 \mathrm{~K})$ and pressure $(101.325 \mathrm{kPa})$ conditions (STP) and keep the set flow rates constant throughout the measurement period. The flow rate is chosen on the premise that the $\mathrm{CO}_{2}$ level should not exceed $1.00 \%$ and measurement of $\mathrm{O}_{2}$ consumption should still be possible. For lactating dairy cows, the flow rate usually used is $1.3 \mathrm{~L} / \mathrm{min}$ for each kilogram of live $\mathrm{BW}$, and for heifers and nonlactating dairy cows, the flow rate is 1.0 $\mathrm{L} /$ min for each kilogram of $\mathrm{BW}$.
At the flow-through system described herein, the air is pulled and the flow rate measurement takes place downstream from the respiration chamber (in the excurrent air stream). This approach, together with adjustments in the fresh air inlet valve, always ensures a slight negative pressure (minimal 50 and maximal 100 $\mathrm{Pa}$ below ambient pressure) inside the chamber, thus preventing leakages out of the system. The pressure inside the chamber is measured with a digital pressure indicator (DPI 705, Druck Limited, Leicester, UK) every morning before starting the measurements.

The 4 chambers share a common gas analysis and data acquisition system (Sable Systems International). After the measurement of the flow rate, air leaving the chamber is continuously sampled at about $0.5 \mathrm{~L} / \mathrm{min}$ by the flow meter's internal subsampling pump for analysis, and then the overflow is exhausted. The ambient air (baseline) is also continuously subsampled at about $0.5 \mathrm{~L} / \mathrm{min}$ by a positive pressure pump (B-pump, Sable Systems International). A gas switching system with 8 channels (RM-8 Flow Multiplexer, Sable Systems International) controls the 4 chamber and baseline air samples, and delivers only one sample stream (from one of the chambers or baseline) to the analyzer set at any time by a means of a diaphragm subsampling pump (SS-4 Sub-Sampler Pump, Sable Systems International; Figure 1). Flow leaving the multiplexer at 0.5 $\mathrm{L} / \mathrm{min}$ is pulled by the subsampling pump at $0.2 \mathrm{~L} / \mathrm{min}$ through a sampling manifold (T-connection); then, the excess air escapes and the controlled flow $(0.2 \mathrm{~L} / \mathrm{min})$ is pushed through the analysis chain. All tubing from the subsampling pumps to the gas analyzers uses Bev- 
A-Line IV tubes, size B5 (Excelon, Long Hill Township, NJ).

The time interval at which the multiplexer switches the channels can be defined by the operator in the data acquisition software (Expedata Data Analysis Software 1.8.5, version PRO, Sable Systems International), based on the stability of the gas concentrations and the number of chambers in operation. At present, the system is configured to $200 \mathrm{~s}$ of measuring time for each channel (dwell time). With all 4 chambers working simultaneously, the switching sequence in each measurement cycle follows the pattern: baseline, chamber 1 , chamber 2, baseline, chamber 3, chamber 4 . Using this approach, the time required for a complete cycle through all chambers (cycle time) is $20 \mathrm{~min}$ and we have 3 measurements per hour for each chamber and 66 measurements in $1 \mathrm{~d}$ (considering a measurement period of $22 \mathrm{~h} / \mathrm{d}$ ).

The sample stream is delivered in sequence to the water vapor (RH-300 Water Vapor Analyzer), $\mathrm{CO}_{2}$ (CA10A Carbon Dioxide Analyzer), $\mathrm{CH}_{4}$ (MA-10Methane Analyzer), and $\mathrm{O}_{2}$ (FC-10 Oxygen Analyzer) analyzers (Figure 1; all from Sable Systems International). The lag time of each analyzer depends on the length of the Bev-A-Line tubes between the gas switching system and the respective analyzer, and on the subsampling rate. Using a subsampling rate of $0.2 \mathrm{~L} / \mathrm{min}$, the lag time of the water vapor, $\mathrm{CO}_{2}, \mathrm{CH}_{4}$, and $\mathrm{O}_{2}$ analyzers are $9,11,16$, and $23 \mathrm{~s}$, respectively. Carbon dioxide and methane are measured using infrared technology, whereas oxygen is measured using fuel cell technology. The gas analyzers have an internal temperature control and barometric pressure compensation, so the readout is already corrected to STP conditions. The detection range for relative humidity, $\mathrm{CO}_{2}, \mathrm{CH}_{4}$, and $\mathrm{O}_{2}$ are $0-100 \%$ (accuracy $2 \%$ absolute, resolution $0.001 \%$ ), $0-10 \%$ (accuracy $1 \%$ of reading, resolution $0.0001 \%$ ), 0-10\% (accuracy 1\% of reading, resolution $0.001 \%$ ), and $0-100 \%$ (accuracy $0.1 \%$ of reading, resolution $0.0001 \%)$, respectively.

Calibration of the $\mathrm{CO}_{2}$ and $\mathrm{CH}_{4}$ analyzers (zero and span) is made before the beginning of each measurement. The $\mathrm{O}_{2}$ and water vapor analyzers are calibrated once a week. For zeroing the $\mathrm{CO}_{2}, \mathrm{CH}_{4}$, and $\mathrm{O}_{2}$ analyzers, nitrogen gas (99.999\%) is used, and $\mathrm{CO}_{2}$ and $\mathrm{CH}_{4}$ are spanned by using a mixed gas $\left(0.5 \% \mathrm{CO}_{2}, 0.1 \% \mathrm{CH}_{4}\right.$ in $\mathrm{N}_{2}$ as carrier). The $\mathrm{O}_{2}$ analyzer is spanned with dry ambient air, scrubbed from water by using magnesium perchlorate, as it shows an almost constant concentration of $20.95 \%$. A zero value of the water vapor analyzer is achieved with the dry air, and the value for spanning is calculated following the Lighton (2008) equation:

$$
\mathrm{WVP}=\mathrm{BP} \times\left[\left(\mathrm{F}^{\prime} \mathrm{iO}_{2}-\mathrm{FiO}_{2}\right) / \mathrm{F}^{\prime} \mathrm{iO}_{2}\right],
$$

where WVP is the water vapor pressure in the same units as barometric pressure $(\mathrm{kPa})$; $\mathrm{BP}$ is the barometric pressure; and $\mathrm{F}^{\prime} \mathrm{iO}_{2}$ and $\mathrm{FiO}_{2}$ are $\mathrm{O}_{2}$ fractional concentrations of dry and wet ambient air, respectively.

A recovery test of the whole system was made by injection of known volumes of $\mathrm{CO}_{2}$ and $\mathrm{CH}_{4}$ in each chamber, by using a portable mass flowmeter with totalizer function (MC-50SLPM-D, Alicat Scientific Inc., Tucson, AZ). The average recoveries for $\mathrm{CO}_{2}$ and $\mathrm{CH}_{4}$ were $($ mean $\pm \mathrm{SD}) 99.0 \pm 2.1 \%$ and $98.0 \pm 2.7 \%$, respectively.

Each chamber contains a feed bin $(0.7 \mathrm{~m}$ wide, 1.0 $\mathrm{m}$ high, and $0.5 \mathrm{~m}$ deep) made from stainless steel and equipped with load cells (100-kg weighing capacity with \pm 25 g accuracy), an electronic gate for animal access control, and a registration device (Intergado Ltd., Minas Gerais, Brazil; Figure 2B). For each bin visit, the system records the duration and feed disappearance using a data collector via network cable and transfer to the Intergado web software via a general packet radio service. The feed bins are equipped with an automatic gate allowing feeding (release access to feed) without opening the chamber. Around $30 \mathrm{~min}$ after closing the chamber, the feed bin gate is opened and the evaluation of gaseous exchange and feed intake start. This waiting period following the door closure aims to minimize the measurement while the chamber air is transient; that is, the gas content is modified quickly by the animal.

Once a week, the feed system is calibrated with a $25-\mathrm{kg}$ analytical precision weight (Intergado Ltd.), following the manufacturer's instructions. Water intake is registered by water meters equipped with electromechanical registration, and this system is checked periodically by removing a known volume of water from the bin to compare with the value registered. Animal position, depicted as standing or lying, is registered by a photoelectric switch (Intergado Ltd.). To monitor animal behavior and wellbeing, each chamber is equipped with an infrared camera (VM 310 IR, Intelbras S/A, Santa Catarina, Brazil) plugged into a video recording system, which enables animals to be observed from a video monitor located in the control room, as well as remote monitoring by staff members. The animal position registered by the photoelectric switch can be checked by the video recordings, when necessary. The animal's heart rate (HR) inside the chamber is recorded with a Polar transmitter and monitor (model RS800CX G3, Polar Electro Inc., Kempele, Finland).

Data acquisition and analysis software (ExpeData v.1.7.5, Sable Systems International) is used to record 
gas concentration for $\mathrm{O}_{2}, \mathrm{CO}_{2}$, and $\mathrm{CH}_{4}$; wet air outflow rate; temperature; barometric pressure; and water vapor pressure during the measurement period. The software, by means of a macro utility, corrects the effect of water vapor on flow rate and gas concentrations, performs lag time correction, response correction and drift correction. The gas concentration data are corrected for lag by deleting the first " $n$ " seconds in that channel; that is, the time of each analyzer to encounter the air sample, and shifting all remaining data " $n$ " seconds to the left. The gas concentrations are corrected for differences in response time by applying the instantaneous transform, also known as the Z-transform (Bartholomew et al., 1981; Lighton, 2008). Response correction coefficients were $0.134,0.189,0.047$, and 0.137 for $\mathrm{O}_{2}, \mathrm{CO}_{2}$, water vapor, and $\mathrm{CH}_{4}$, respectively. From the measurements of air entering (incurrent) and air leaving (excurrent) the chambers, the software calculates the exhaustion rates $(\mathrm{L} / \mathrm{min})$ of $\mathrm{O}_{2}\left(\mathbf{V O}_{2}\right), \mathrm{CO}_{2}\left(\mathbf{V} \mathbf{C O}_{2}\right)$, and $\mathrm{CH}_{4}$ $\left(\mathbf{V C H}_{4}\right)$ from each chamber, using the following equations from Lighton (2008):

$$
\begin{aligned}
\mathrm{VO}_{2}= & \mathrm{FR} \times\left[\left(\mathrm{FiO}_{2}-\mathrm{FeO}_{2}\right)-\mathrm{FiO}_{2}\right. \\
\times & \left(\mathrm{FeCO}_{2}-\mathrm{FiCO}_{2}\right)-\mathrm{FiO}_{2} \\
\times & \left.\left(\mathrm{FeCH}_{4}-\mathrm{FiCH}_{4}\right)\right] /\left(1-\mathrm{FiO}_{2}\right), \\
\mathrm{VCO}_{2}= & \mathrm{FR} \times\left[\left(\mathrm{FeCO}_{2}-\mathrm{FiCO}_{2}\right)+\mathrm{FiCO}_{2}\right. \\
& \times\left(\mathrm{FiO}_{2}-\mathrm{FeO}_{2}\right)+\mathrm{FiCO}_{2} \\
\times & \left.\left(\mathrm{FeCH}_{4}-\mathrm{FiCH}_{4}\right)\right] /\left(1+\mathrm{FiCO}_{2}\right), \\
\mathrm{VCH}_{4}= & \mathrm{FR} \times\left[\left(\mathrm{FeCH}_{4}-\mathrm{FiCH}_{4}\right)+\mathrm{FiCH}_{4}\right. \\
& \times\left(\mathrm{FiO}_{2}-\mathrm{FeO}_{2}\right)+\mathrm{FiCH}_{4} \\
\times & \left.\left(\mathrm{FeCO}_{2}-\mathrm{FiCO}_{2}\right)\right] /\left(1+\mathrm{FiCH}_{4}\right),
\end{aligned}
$$

where $\mathrm{FR}$ is the flow rate; $\mathrm{FiO}_{2}, \mathrm{FiCO}_{2}$, and $\mathrm{FiCH}_{4}$ are the fractional concentrations of $\mathrm{O}_{2}, \mathrm{CO}_{2}$, and $\mathrm{CH}_{4}$ of the incurrent air; and $\mathrm{FeO}_{2}, \mathrm{FeCO}_{2}$, and $\mathrm{FeCH}_{4}$ are the fractional excurrent concentrations of $\mathrm{O}_{2}, \mathrm{CO}_{2}$, and $\mathrm{CH}_{4}$. After $\mathrm{VO}_{2}, \mathrm{VCO}_{2}$, and $\mathrm{VCH}_{4}$ have been calculated for each sample point, the mean is taken for the central 180 consecutive samples of each 200-sample data section for each chamber during each measurement cycle of 20 min. Besides the rate of gas exhaustion from the chambers, the rate of change in gas content inside the chamber is also calculated as the difference in the volume of $\mathrm{O}_{2}, \mathrm{CO}_{2}$, and $\mathrm{CH}_{4}$ between each measurement cycle; that is, the chamber gas concentrations are multiplied by the known volume of chamber corrected for pressure and temperature. The difference of chamber gas content between sequential measurements and the gas exhaustion rate are then summed over each cycle to calculate the total gas exchange for $\mathrm{O}_{2}, \mathrm{CO}_{2}$, and $\mathrm{CH}_{4}$, which means the rate of gas consumption by, and emission from, the animal. The data recorded over $24 \mathrm{~h}$ are exported and used as input for $\mathrm{R}$ for integration and data analysis using a R-dedicated package developed to this particular system, which allows easy data integration with all sensor platforms. Data between each measurement time and missing data when the chambers are open (for animal feeding and milking) are estimated by interpolation (penalized spline model). The daily gas exchanges are calculated by integration (spline/ area under curve). Data of feeding and water intake, standing time, standing or lying position and HR are integrated to data of $\mathrm{CH}_{4}$ emission and heat production (HP) calculated according to Brouwer (1965), and reports and graphics from $\mathrm{R}$ software are generated.

We conducted a trial with 12 lactating $3 / 4$ Holstein $\times 1 / 4$ Gyr crossbred dairy cows (6 multiparous and 6 primiparous) at $157.6 \pm 6.9$ DIM to evaluate the system. The cows were fed a TMR consisting of 443.1 $\mathrm{g} / \mathrm{kg}$ maize silage, $79.1 \mathrm{~g} / \mathrm{kg}$ Tifton hay, and $477.8 \mathrm{~g} /$ $\mathrm{kg}$ concentrate, on a DM basis $(\mathrm{DM}=486.6 \mathrm{~g} / \mathrm{kg}$; $\left.\mathrm{CP}=177.8 \mathrm{~g} / \mathrm{kg} ; \mathrm{NE}_{\mathrm{L}}=1.61 \mathrm{Mcal} / \mathrm{kg}\right)$. Cows were distributed in 2 feed regimens from $30 \mathrm{~d}$ postpartum: ad libitum $(\mathbf{A L})$ or restricted to provide $80 \%$ of $\mathrm{NE}_{\mathrm{L}}$ requirements (RE), according to NRC (2001). The cows were milked at 0630 and $1400 \mathrm{~h}$ and fed at 0700 and $1430 \mathrm{~h}$. The daily milk yield and feed intake were recorded. Animals were halter-trained and adapted to handling and to respiration chambers before the trial began. Starting after the morning milking, two 22-h respiration measurements were obtained from each cow. For each respiration measurement, the cow was randomly allocated to one chamber. The feed intake and milk production inside the chamber were compared with the average feed intake and milk yield during the week before the respiration trial and, if these values dropped more than $5 \%$, the respiration measurement was repeated. For this trial, urinary nitrogen was neglected in Brouwer's equation, because it gives a very small contribution to $\mathrm{HP}$ compared with $\mathrm{O}_{2}$ and $\mathrm{CO}_{2}$ (Verstegen et al., 1987). All animals were weighed on the way to and from the chambers. The circulated air inside the chambers was maintained at $55 \% \mathrm{RH}$ and $22^{\circ} \mathrm{C}$. A mixed model was used to examine the components of variation for all variables. The mixed model included fixed effects for feed regimen, day, and parity. Random effects included in the model were cow and day within cow. The estimated components of variation were used to calculate the coefficient of variation (b) within cow and between cows. Repeatability of $\mathrm{CH}_{4}$ emission was calculated as the proportion of variance between animals with respect to the total variance. 


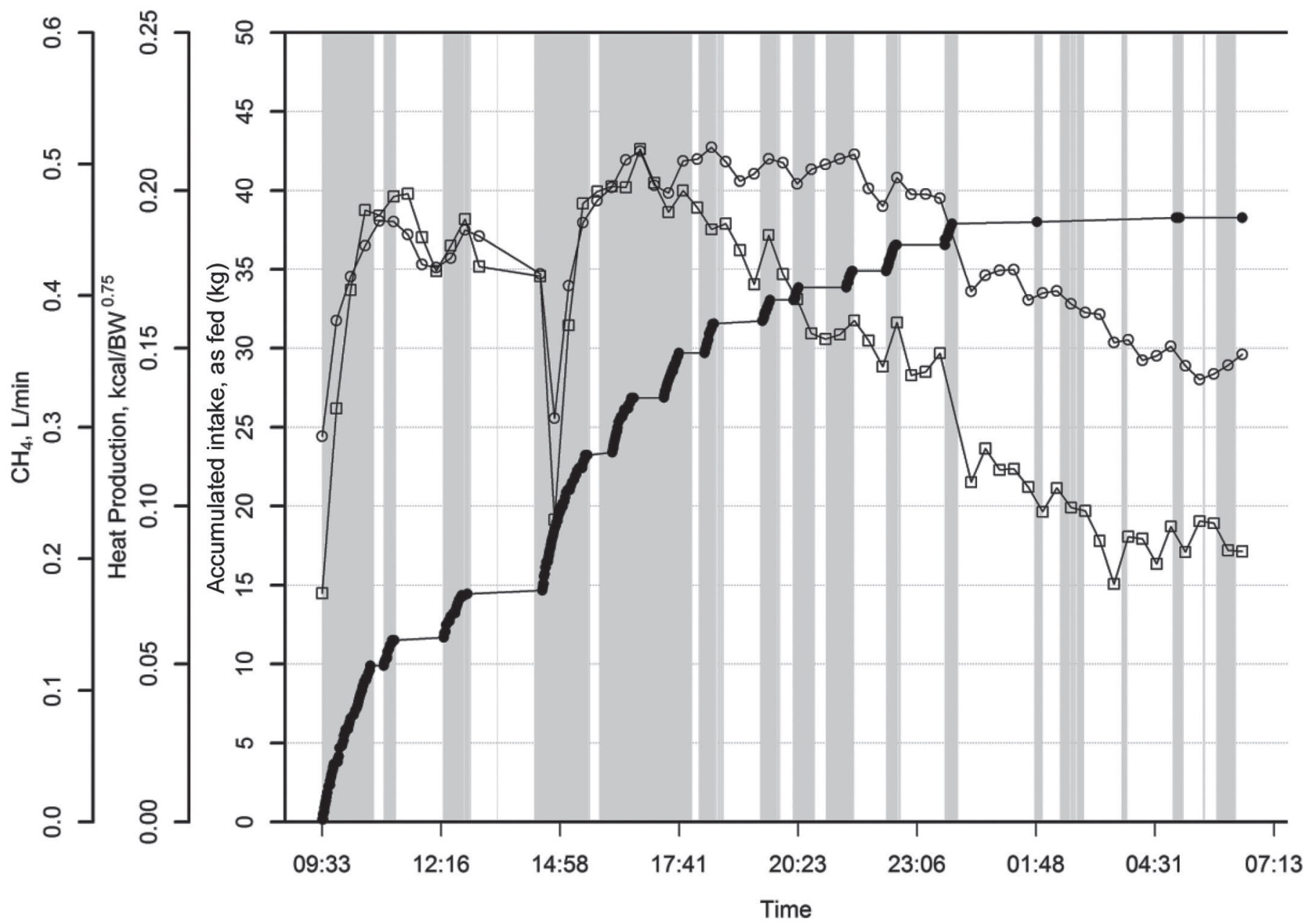

Figure 3. Dynamics of accumulated feed intake $(\bullet)$, heat production $(\bigcirc)$, and methane emission $(\square)$, and standing time (shaded areas) of one cow during the respiration trial. Heat production and methane emission levels decreased around $1500 \mathrm{~h}$ because the chamber was opened for milking and feeding procedures.

The AL-fed multiparous and primiparous cows had an average live weight of $584 \pm 41 \mathrm{~kg}$ and $544 \pm 21 \mathrm{~kg}$, respectively. The RE-fed multiparous and primiparous cows had an average live weight of $497 \pm 22 \mathrm{~kg}$ and 455 $\pm 25 \mathrm{~kg}$, respectively. All RE-fed cows showed similar feed intake the week before and during chamber stay, because there were no orts due to the limited feed supply. Three AL-fed cows, 2 primiparous and 1 multiparous, dropped more than 5\% in DMI when they were transferred to the respiration chambers; therefore, it was necessary to take one more respiration measurement for these animals. Two cows (\#1 and \#7) under the $\mathrm{AL}$ regimen showed variation in $\mathrm{DMI}>5 \%$ (6.4 and $9.2 \%$, respectively) between first and second day of evaluation inside the chambers. However, DMI recorded during the 2 respiration measurements was still within the admissible range regarding the average DMI observed the previous week outside the chambers for the respective cows.
The dynamics of heat production, $\mathrm{CH}_{4}$ emission, feed intake, and position changes measured during the stay of one individual cow in one of the chambers is shown in Figure 3. Feed consumption, milk production, and components of energy expenditure data are presented in Table 1. As expected, RE-fed multiparous and primiparous cows showed lower values for methane emission and HP than AL-fed animals. No differences between primiparous and multiparous were observed for the parameters evaluated because the primiparous cows used in the present trial had already reached their mature weight. The $35 \%$ reduction in DMI for RE-fed multiparous compared with AL-fed multiparous cows led to reductions in $\mathrm{CH}_{4}$ production and $\mathrm{HP}$ of 33 and $28 \%$, respectively. The $31 \%$ reduction in DMI by for RE-fed primiparous cows reduced the $\mathrm{CH}_{4}$ production and HP by 29 and $21 \%$, respectively. We detected no difference among groups for $\mathrm{CH}_{4}$ produced per kilogram of DMI (Table 1). The within-animal (day-to-day 
Table 1. Feed intake, milk yield, methane emission, heat production, and respiration quotient (RQ) in primiparous (P) and multiparous (M) dairy cows under 2 feeding regimens: ad libitum (AL) or restricted (RE)

\begin{tabular}{|c|c|c|c|c|c|c|c|c|c|c|c|c|c|c|c|c|}
\hline \multirow[b]{3}{*}{ Cow } & \multirow[b]{3}{*}{ Parity } & \multirow{3}{*}{$\begin{array}{l}\text { Feeding } \\
\text { regimen }\end{array}$} & & & \multicolumn{12}{|c|}{ Measured parameter } \\
\hline & & & \multicolumn{2}{|c|}{ Chamber } & \multicolumn{2}{|c|}{ DMI, kg } & \multicolumn{2}{|c|}{ Milk yield, kg } & \multicolumn{2}{|c|}{$\mathrm{CH}_{4}, \mathrm{~L}$} & \multicolumn{2}{|c|}{$\begin{array}{c}\mathrm{CH}_{4} \\
\mathrm{~L} / \mathrm{kg} \text { of } \mathrm{DMI}\end{array}$} & \multicolumn{2}{|c|}{$\begin{array}{l}\text { Heat production, } \\
\mathrm{kcal} / \mathrm{kg}^{0.75} \text { per } \\
\text { day }\end{array}$} & \multicolumn{2}{|c|}{ RQ } \\
\hline & & & Day 1 & Day 2 & Day 1 & Day 2 & Day 1 & Day 2 & Day 1 & Day 2 & Day 1 & Day 2 & Day 1 & Day 2 & Day 1 & Day 2 \\
\hline 1 & $\mathrm{P}$ & $\mathrm{AL}$ & 4 & 1 & 22.8 & 20.9 & 20.9 & 19.3 & 573 & 561 & 25.1 & 26.9 & 245 & 244 & 1.17 & 1.13 \\
\hline 2 & $\mathrm{P}$ & $\mathrm{AL}$ & 2 & 3 & 18.6 & 17.8 & 19.2 & 20.8 & 471 & 464 & 25.3 & 26.0 & 260 & 253 & 1.14 & 1.10 \\
\hline 3 & $\mathrm{P}$ & $\mathrm{AL}$ & 2 & 4 & 18.1 & 18.5 & 16.6 & 15.7 & 529 & 519 & 29.2 & 28.1 & 227 & 228 & 1.14 & 1.14 \\
\hline \multicolumn{5}{|c|}{ Mean (SD) } & \multicolumn{2}{|c|}{$19.4(1.95)$} & \multicolumn{2}{|c|}{$18.8(2.2)$} & \multicolumn{2}{|c|}{519} & \multicolumn{2}{|c|}{$26.8(1.6)$} & \multicolumn{2}{|c|}{$243(13)$} & \multicolumn{2}{|c|}{$1.14(0.02)$} \\
\hline 4 & $\mathrm{P}$ & $\mathrm{RE}$ & 3 & 4 & 13.7 & 13.7 & 17.2 & 17.5 & 404 & 394 & 29.4 & 28.7 & 196 & 194 & 1.16 & 1.16 \\
\hline 5 & $\mathrm{P}$ & $\mathrm{RE}$ & 2 & 1 & 15.1 & 15.1 & 22.1 & 21.3 & 399 & 401 & 26.4 & 26.5 & 205 & 200 & 1.09 & 1.10 \\
\hline 6 & $\mathrm{P}$ & $\mathrm{RE}$ & 3 & 4 & 11.1 & 11.1 & 12.9 & 13.4 & 298 & 303 & 26.8 & 27.3 & 177 & 177 & 1.05 & 1.08 \\
\hline \multicolumn{5}{|c|}{ Mean (SD) } & \multicolumn{2}{|c|}{$13.3(1.8)$} & \multicolumn{2}{|c|}{$17.4(3.8)$} & \multicolumn{2}{|c|}{$367(51)$} & \multicolumn{2}{|c|}{$27.5(1.3)$} & \multicolumn{2}{|c|}{$191(12)$} & \multicolumn{2}{|c|}{$1.11(0.05)$} \\
\hline 7 & M & $\mathrm{AL}$ & 2 & 4 & 20.7 & 22.1 & 20.3 & 19.5 & 571 & 608 & 27.5 & 27.5 & 249 & 259 & 1.11 & 1.13 \\
\hline 8 & M & $\mathrm{AL}$ & 3 & 2 & 21.7 & 21.4 & 25.1 & 24.1 & 550 & 585 & 25.4 & 27.3 & 273 & 276 & 1.08 & 1.16 \\
\hline 9 & M & $\mathrm{AL}$ & 3 & 4 & 20.6 & 20.0 & 22.0 & 22.8 & 497 & 491 & 24.1 & 24.5 & 249 & 239 & 1.09 & 1.14 \\
\hline \multicolumn{5}{|c|}{ Mean (SD) } & \multicolumn{2}{|c|}{$21.1(0.8)$} & \multicolumn{2}{|c|}{$22.3(2.2)$} & \multicolumn{2}{|c|}{$550(48)$} & 26.1 & (1.6) & 258 & (15) & 1.12 & $0.03)$ \\
\hline 10 & M & $\mathrm{RE}$ & 2 & 1 & 14.8 & 14.8 & 19.0 & 19.9 & 398 & 385 & 27.0 & 26.1 & 185 & 175 & 1.12 & 1.13 \\
\hline 11 & $\mathrm{M}$ & $\mathrm{RE}$ & 3 & 4 & 12.2 & 12.2 & 15.3 & 11.7 & 389 & 372 & 31.8 & 30.4 & 183 & 176 & 1.12 & 1.12 \\
\hline 12 & M & $\mathrm{RE}$ & 1 & 2 & 14.0 & 14.0 & 14.3 & 16.5 & 330 & 335 & 23.5 & 23.8 & 194 & 197 & 1.05 & 1.10 \\
\hline Mean & & & & & 13.7 & $(1.2)$ & 16.1 & & 368 & (29) & 27.1 & $(3.4)$ & 185 & (9) & 1.11 & $0.03)$ \\
\hline With & ariance & & & & 0.2 & & 1.2 & & 63. & & 0.3 & & & 23 & 0.00 & \\
\hline Betw & variance & & & & 2.4 & & 8.6 & & 2,264 . & & 5.0 & & & 14 & 0.00 & \\
\hline Total & & & & & 2.7 & & 9.9 & & 2,327 . & & 5.4 & & & & 0.00 & \\
\hline Repe & & & & & 0.9 & & 0.8 & & & 97 & 0.9 & & & .92 & 0.74 & \\
\hline
\end{tabular}


variation) $\mathrm{CV}$ were 1.8 and $2.3 \%$ for $\mathrm{CH}_{4}$ emissions measured in liters per day and liters per kilogram of DMI, respectively; and the between-animal $\mathrm{CV}$ were 10.6 and $8.4 \%$ for these parameters. For HP, the within- and between-animal CV were 1.7 and $5.9 \%$, respectively. Estimates of repeatability (total variation/ variation between animals) for $\mathrm{CH}_{4}$ emission and heat production were high (Table 1). Repeatability for individual animals over time needs to be high to reliably detect high and low $\mathrm{CH}_{4}$-emitting animals (Vlaming et al., 2008), as well as more- and less-efficient animals through respiration trials. The results presented here showed variation consistent with findings from the previous studies of Blaxter and Clapperton (1965) and Grainger et al. (2007), which obtained within-animal CV of 7.2 and $4.3 \%$, respectively, for $\mathrm{CH}_{4}$ measures using respiration chambers.

In conclusion, the respiration system described is a useful tool for measuring the dynamic and accumulated data of HP, methane emission, and feed intake and its interactions with animal genetics, nutritional management, and climatic conditions.

\section{ACKNOWLEDGMENTS}

Authors are grateful to Coordenação de Aperfeiçoamento de Pessoal de Nível Superior (CAPES, Brasília, Brazil), Conselho Nacional de Desenvolvimento Científico e Tecnológico (CNPq, Brasília, Brazil), Secretaria de Estado de Ciência e Tecnologia e Ensino Superior do Estado de Minas Gerais, Polo de Excelência do Leite (SECTES-MG, Belo Horizonte, Brazil), Fundação de Amparo à Pesquisa do estado de Minas Gerais (FAPEMIG, Belo Horizonte, Brazil), CAPES-PVE (CAPESPesquisador Visitante Especial, Brasília, Brazil), and Embrapa (Brasília, Brazil) for funding this project.

\section{REFERENCES}

Aguilera, J. F., and C. Prieto. 1986. Description and function of an open-circuit respiration plant for pigs and small ruminants and the techniques used to measure energy metabolism. Arch. Tierernahr. 36:1009-1018.

Arndt, C., J. M. Powell, M. J. Aguerre, P. M. Crump, and M. A. Wattiaux. 2015. Feed conversion efficiency in dairy cows: Repeatability, variation in digestion and metabolism of energy and nitrogen, and ruminal methanogens. J. Dairy Sci. 98:3938-3950.

Bartholomew, G. A., D. Vleck, and C. M. Vleck. 1981. Instantaneous measurements of oxygen consumption during pre-flight warm-up and post-flight cooling in sphingid and saturniid moths. J. Exp. Biol. 90:17-32.

Blaxter, K. L., and J. L. Clapperton. 1965. Prediction of the amount of methane produced by ruminants. Br. J. Nutr. 19:511-522.

Brouwer, E. 1965. Report of sub-committee on constants and factors. Pages 441-443 in Energy Metabolism of Farm Animals, Academic Press, London, UK.

Derno, M., H. G. Elsner, E. A. Paetow, H. Scholze, and M. Schweigel. 2009. Technical note: A new facility for continuous respiration measurements in lactating cows. J. Dairy Sci. 92:2804-2808.

Derno, M., W. Jentsch, M. Schweigel, S. Kuhla, C. C. Metges, and H.D. Matthes. 2005. Measurements of heat production for estimation of maintenance energy requirements of Hereford steers. J. Anim. Sci. 83:2590-2597.

Grainger, C., T. Clarke, S. M. McGinn, M. J. Auldist, K. A. Beauchemin, M. C. Hannah, G. C. Waghorn, H. Clark, and R. J. Eckard 2007. Methane emissions from dairy cows measured using the sulfur hexafluoride $\left(\mathrm{SF}_{6}\right)$ tracer and chamber techniques. J. Dairy Sci. 90:2755-2766

Lighton, J. R. B. 2008. Measuring Metabolic Rates: A Manual for Scientists. Oxford University Press, Oxford, UK.

Moraes, L. E., E. Kebreab, A. B. Strathe, J. Dijkstra, J. France, D. P. Casper, and J. G. Fadel. 2015. Multivariate and univariate analysis of energy balance data from lactating dairy cow. J. Dairy Sci. 98:4012-4029.

NRC. 2001. Nutrient Requirements of Dairy Cattle. 7th rev. ed. National Academies Press, Washington, DC.

Verstegen, M. W. A., W. Van der Hel, H. A. Brandsma, A. M. Henken, and A. M. Bransen. 1987. The Wageningen respiration unit for animal production research: A description of the equipment and its possibilities. Pages 21-48 in Energy Metabolism in Farm Animals: Effects of Housing, Stress and Disease. M. W. A. Verstegen, and A. M. Henken, ed. MartinusNijhoff Publishers, Dordrecht, the Netherlands.

Vlaming, J. B., N. Lopez-Villalobos, I. M. Brookes, S. O. Hoskin, and H. Clark. 2008. Within- and between-animal variance in methane emissions in non-lactating dairy cows. Aust. J. Exp. Agric. $48: 124-127$

Yan, T., F. J. Gordon, R. E. Agnew, M. G. Porter, and D. C. Patterson. 1997. The metabolisable energy requirement for maintenance and the efficiency of utilization of metabolisable energy for lactation by dairy cows offered grass silage-based diets. Livest. Prod. Sci. 51:141-150. 